\title{
PRÁTICAS PEDAGÓGICAS NO CONTEXTO DA CULTURA DIGITAL: UM ESTUDO DE CASO
}

\author{
Karina MARCONi \\ Juliana Brandão MACHADO ${ }^{\text {ii }}$ \\ João Victor SCHMITZ ${ }^{\text {iii }}$ \\ Leonardo José ROSSI ${ }^{i v}$
}

\begin{abstract}
RESUMO
Este artigo apresenta resultados de uma pesquisa cujo objetivo foi investigar as relações teórico-práticas dos processos de inclusão digital nos espaços educativos escolares da Rede Municipal de Ensino de Florianópolis/Santa Catarina, tendo o conceito de inclusão digital com base em Marcon (2008) como referência. O estudo qualitativo, de natureza exploratória, apresenta um recorte de observações simples realizadas em sete escolas sobre o desenvolvimento de práticas pedagógicas nas salas informatizadas, com turmas do $4^{\circ}$ ou $5^{\circ}$ ano do Ensino Fundamental. Os resultados indicam que as escolas vêm trabalhando em uma perspectiva de inclusão digital, com planejamento intencional, variação de recursos tecnológicos, docência compartilhada e interação entre professores/as regentes e auxiliares de tecnologias educacionais.
\end{abstract}

PALAVRAS-CHAVE: Inclusão digital; Cultura digital; Escola; Práticas pedagógicas; Sala informatizada.

\section{PEDAGOGICAL PRACTICES IN THE CONTEXT OF DIGITAL CULTURE: A CASE STUDY}

\begin{abstract}
This article presents results of a research whose objective was to investigate the theoretical-practical relationships of digital inclusion processes in school educational spaces of the Municipal Education Network of Florianópolis, Santa Catarina, Brazil, having the concept of digital inclusion based on Marcon (2008) as reference. The qualitative study, of an exploratory nature, presents a cutoff of simple observations made in seven schools on the development of pedagogical practices in computing

\footnotetext{
${ }^{\text {i }}$ Doutorado em Educação pela Universidade Federal do Rio Grande do Sul. Professora Adjunta da Universidade do Estado de Santa Catarina (Udesc); docente do Mestrado Profissional em Educação Inclusiva em Rede Profei/Udesc. E-mail: karina.marcon@ udesc.br - ORCID iD: https://orcid.org/0000-0002-3842-5296.

ii Doutorado em Educação pela Universidade Federal do Rio Grande do Sul. Professora Adjunta da Universidade Federal do Pampa (Unipampa); docente do Programa de Pós-graduação em Educação - PPGEdu/UNIPAMPA. E-mail: julianamachado@ unipampa.edu.br - ORCID iD: https://orcid.org/0000-0003-0181-317X.

iii Licenciando em História e Bolsista de Iniciação Científica (PIPES - Programa de Iniciação à Pesquisa) na Universidade do Estado de Santa Catarina (Udesc). E-mail: schmitzjoaovictor@gmail.com - ORCID iD: https://orcid.org/0000-0001-5557-8430.

iv Licenciando em História e Bolsista de Iniciação Científica (PIPES - Programa de Iniciação à Pesquisa) na Universidade do Estado de Santa Catarina (Udesc). E-mail: leonardojoserossi16@gmail.com - ORCID iD: https://orcid.org/0000-0003-1067-9806.
} 
classrooms, with classes from the 4th or 5th grade of Elementary School. The results indicate that schools have been working in a digital inclusion perspective, with intentional planning, variation of technological resources, shared teaching and interaction among teachers and educational technology assistants.

KEYWORDS: Digital inclusion; Digital culture; School; Pedagogical practices; Computing classroom.

\section{PRÁCTICAS PEDAGÓGICAS EN EL CONTEXTO DE LA CULTURA DIGITAL: UN ESTUDIO DE CASO}

\section{RESUMEN}

Este artículo presenta resultados de una investigación cuyo objetivo fue investigar las relaciones teórico-prácticas de los procesos de inclusión digital en los espacios educativos escolares de la Red Municipal de Educación de Florianópolis, Santa Catarina, Brasil, teniendo como referencia el concepto de inclusión digital basado en Marcon (2008). El estudio cualitativo, de naturaleza exploratoria, presenta un recorte de observaciones simples realizadas en siete escuelas sobre el desarrollo de prácticas pedagógicas en las aulas informatizadas, con clases de 4to o 5to año de Educación Primaria. Los resultados indican que las escuelas han estado trabajando desde una perspectiva de inclusión digital, con planificación intencional, variación de recursos tecnológicos, docencia compartida e

interacción entre maestros/as y asistentes de tecnologías educativas.

PALABRAS CLAVE: Inclusión digital; Cultura digital; Escuela; Prácticas pedagógicas; Aula informatizada.

\section{INTRODUÇÃO}

Este artigo apresenta alguns resultados da pesquisa "Inclusão digital em contextos educativos escolares: um estudo sobre a Rede Municipal de Ensino de Florianópolis/SC"1, desenvolvida na Universidade do Estado de Santa Catarina (Udesc), no Centro de Educação a Distância, a qual tem o objetivo principal de investigar as relações teórico-práticas dos processos de inclusão digital em espaços educativos escolares da Rede Municipal de Ensino (RME) de Florianópolis, Santa Catarina. Esse estudo surgiu da necessidade de acompanhar as discussões sobre os processos de inclusão digital em contextos escolares, tema que já vinha sendo pesquisado em projetos anteriores (MARCON, 2008, 2015). Ainda, sentia-se a necessidade de conhecer os processos de inclusão digital da RME de Florianópolis, em busca de considerar a indissociabilidade entre ensino, pesquisa e extensão, bem como a aproximação da Universidade com a escola. 
O projeto foi desenvolvido com o objetivo de responder ao seguinte problema de pesquisa: De que forma estão acontecendo os processos de inclusão digital nos espaços educativos escolares da Rede Municipal de Ensino de Florianópolis/SC? Outros questionamentos surgiram a partir do problema central da pesquisa: Como é concebido, pela equipe docente e gestora das escolas, o conceito de inclusão digital? Existem práticas pedagógicas envolvendo outras tecnologias digitais (celulares, smartphones, tablets, notebooks)?

Ao elaborarmos o projeto, tínhamos como hipótese que os processos de apropriação das tecnologias digitais nas escolas podem estar acontecendo de três formas. Na primeira, as práticas pedagógicas docentes acontecem de forma autoral e participativa/colaborativa, na qual os/as educandos/as têm se apropriado das tecnologias em situações educacionais que propiciem e explorem características que, em nossa opinião, são inerentes ao contexto social contemporâneo, como a participação, a autoria, a criatividade e a coletividade. Tais atividades podem envolver recursos como blogs, redes sociais, computação nas nuvens, softwares de criação e produção de textos, áudios, vídeos, entre outros. A segunda forma seria de lazer/recreação, na qual os/as educandos/as podem utilizar a sala de informática com atividades sem finalidades pedagógicas intencionais. Nessa hipótese, a sala informatizada poderia ser utilizada para a ocupação de tempos ociosos, na falta de professores/as, por exemplo. A terceira e última hipótese de como a apropriação das tecnologias poderia acontecer nas unidades educativas é a de consumo/reprodução. Pressupomos que os/as educandos/as poderiam apropriar-se das tecnologias digitais em uma perspectiva de consumo, pois as tecnologias vêm sendo utilizadas como instrumentos de pesquisa, prevalecendo atividades instrucionais, como a digitação de textos, leituras, entre outras.

Ressaltamos que essas três hipóteses podem acontecer concomitantemente em uma mesma instituição, e todas, de certo modo, são importantes para pensarmos a inclusão digital. Entretanto, entendemos que os processos de inclusão digital precisam pressupor, além da fluência tecnológica, o exercício da cidadania em rede, e, para que ela aconteça, a apropriação autoral, crítica, criativa, participativa e colaborativa das tecnologias digitais.

Ao admitir a importância da inclusão digital, assim como a urgência de se refletir sobre como vem acontecendo o processo de inclusão digital em contextos escolares, a pesquisa tem um caráter importante ao desvelar as práticas pedagógicas envolvendo tecnologias digitais na 
Educação Básica. O recorte apresentado, neste texto, tem por objetivo analisar as práticas docentes realizadas nas salas informatizadas, a partir das observações simples realizadas nas escolas com crianças do $4^{\circ}$ ou $5^{\circ}$ ano do Ensino Fundamental.

\section{FUNDAMENTAÇÃO TEÓRICA}

A discussão teórica pretende situar, no contexto da cultura digital, as concepções de inclusão digital e os princípios que se desdobram para o desenvolvimento de práticas pedagógicas na Educação Básica. Dessa maneira, apresentaremos as concepções que orientam o trabalho na sala informatizada, considerando o planejamento intencional necessário para o desenvolvimento de práticas pedagógicas que envolvem a apropriação de recursos tecnológicos, bem como as dimensões do conceito de inclusão digital, os quais requerem pensar em uma apropriação crítica das tecnologias e no trabalho colaborativo entre os docentes.

A presença dessas tecnologias na dinâmica escolar faz surgir novas ideias sobre como conceber e viabilizar um planejamento intencional integrado com as tecnologias, as quais envolvam a cooperação e o compartilhamento, características intrínsecas de uma sociedade em rede. Para Veiga (2008, p. 267), “[...] o planejamento de ensino é resultante de um processo integrador entre a instituição educativa e o contexto social, efetivado de forma colaborativa pelos professores e seus alunos". Nesse sentido, o planejamento intencional na sala informatizada precisa considerar a dimensão colaborativa do processo pedagógico, em busca de envolver a participação ativa entre educadores/as e educandos/as.

Dessa maneira, faz-se necessário reconhecer que as práticas pedagógicas desenvolvidas na cultura digital implicam novas relações com os saberes didático-pedagógicos. Kenski (2012), ao apresentar uma discussão sobre educação e tecnologias na perspectiva das redes digitais, aponta como elementos fundamentais a reconstrução dos saberes no processo de ensino, inclusive escolar, e a necessidade de assumirem-se novas formas de aprender no contexto contemporâneo. Superar o pensamento reducionista quanto ao uso instrumental das tecnologias digitais no contexto escolar é um elemento importante no planejamento e no desenvolvimento das práticas pedagógicas (ALONSO et al., 2014).

Assim, é importante indagar se as práticas pedagógicas que envolvem a utilização de tecnologias digitais respondem aos princípios da inclusão digital e caracterizam-se, também, 
pela oportunidade de construção de novos saberes marcados pela autoria, pela participação, pela colaboração e pela criatividade. Ainda que possamos identificar, uma forte "[...] incompatibilidade [...] entre a escola como tecnologia de (outra) época e a garotada de hoje" (SIBILIA, 2012, p. 25), optamos por assumir a ideia do "jogo de complementaridades" proposto por Santaella (2010) entre os processos de educação formal e a aprendizagem ubíqua, procurando reconhecer as suas contribuições para a construção de saberes que oportunizem ao sujeito perfazer os três eixos vinculados ao conceito de inclusão digital.

A situação de conectividade e de proximidade possibilitadas pelas Tecnologias Digitais de Rede (TDR) podem potencializar processos de aprendizagem a partir de "[...] vivências baseadas na interação, na comunicação social e na reflexão compartilhada sobre o objeto de estudo e, principalmente, com aqueles que se dispõem a conhecê-lo" (MARCON, 2008, p. 37). A coexistência das tecnologias nos processos educativos contemporâneos pode contribuir para o desenvolvimento das capacidades cognitivas dos/as educandos/as, desde que estimule o raciocínio, a criatividade, a comunicação e a expressão, além de exercer uma função política essencial na vida contemporânea.

Na mesma direção, Santaella (2010, 2013) apresenta cinco gerações tecnológicas desenvolvidas desde o século XIX: tecnologias do reprodutível, tecnologias da difusão, tecnologias do disponível, tecnologias do acesso e tecnologias da conexão contínua. Nesse caso, as duas últimas referem-se a processos desencadeados a partir do desenvolvimento do computador e da internet, os quais passam a coexistir com as demais gerações. Diante disso, a definição dos recursos tecnológicos a serem integrados no planejamento intencional e no desenvolvimento das práticas pedagógicas precisa avaliar o potencial pedagógico das tecnologias, a partir das suas características.

Nesses processos de apropriação tecnológica desenvolvidos nas escolas, é preciso considerar que a inclusão digital pressupõe movimentos coletivos e descentralizados, nos quais cada sujeito é potencialmente um nó que pode inferir, transformar e dar novas perspectivas para o fluxo da rede. Nesse cenário, a interatividade, a inteligência coletiva e a necessidade de assumir-se como sujeito protagonista e produtor de conteúdos potencializam o exercício da cidadania na rede e invalidam a utilização das tecnologias na perspectiva de consumo.

Pensamos que os projetos, os conceitos e as ações de inclusão digital precisam superar a concepção simplista de acesso e de instrumentalização às tecnologias (ALONSO et al., 2014; 
MACHADO, 2016). A utilização das tecnologias precisa estimular o envolvimento, a criatividade, a curiosidade, elementos que possibilitam ao sujeito a busca e a construção do conhecimento.

Teixeira (2010, p. 33) igualmente aponta a necessidade da “[...] apropriação críticoreflexiva dos fenômenos sociotécnicos numa perspectiva de contextualização sociocultural [...]", a fim de que tal recurso possa, de fato, potencializar e qualificar processos educativos. Assim, é preciso considerar o imbricamento das tecnologias digitais nos processos educativos em prol da criação de estratégias que permitam essa apropriação tecnológica criativa e participativa.

Bonilla (2004) assinala a necessidade de repensarem-se os processos de apropriação tecnológica:

Romper com essa perspectiva implica extrapolar o reducionismo feito ao conceito de inclusão digital e abordá-lo na perspectiva da participação ativa, da produção de cultura e conhecimento, o que implica políticas públicas que invistam efetivamente na capacitação dos/as professores/as, oportunizandolhes condições para questionar, produzir, decidir, transformar, participar da dinâmica social em todas as suas instâncias, bem como trabalhar com seus alunos nessa perspectiva (BONILLA, 2004, p. 1).

Para a autora, é necessário que se supere a visão trivial de inclusão digital como mera utilização das tecnologias. Lemos (2011), igualmente, compreende que a inclusão digital sugere a intensa participação do sujeito na rede, o exercício da cidadania e o posicionamento como produtor de cultura e de conhecimento. Em continuidade, Bonilla (2004) acredita que é urgente pensar na democratização do uso das tecnologias, de modo a permitir aos sujeitos que aprendam com essas tecnologias, que promovam serviços, informações e conhecimentos, e que, principalmente, articulem redes de produção. A articulação dessas redes de produção reflete a dinâmica de compartilhamento e de cooperação que é potencializada pelas tecnologias.

Nesse contexto, entendidos como mais que apenas acesso aos artefatos tecnológicos pertencentes à cultura digital, processos de inclusão digital pressupõem, para além do acesso, o empoderamento, a fluência, a autoria, o exercício da cidadania em rede (LEMOS, 2011). Nessa perspectiva, o conceito de inclusão digital, previamente proposto por Marcon (2015), contribui para a concepção de inclusão digital e a análise dos dados coletados: 
uma dinâmica reticular que privilegia a vivência de características nucleares na sociedade contemporânea, como a interação, a autoria e a colaboração. Inclusão digital pressupõe o empoderamento por meio das tecnologias, a garantia à equidade social e à valorização da diversidade, suprindo necessidades individuais e coletivas, visando à transformação das próprias condições de existência e o exercício da cidadania na rede (MARCON, 2015, p. 99).

Esse conceito perpassaria, portanto, por três eixos:

1) Apropriação/Fluência/Empoderamento Tecnológico.

2) Produção/Autoria individual/coletiva de conhecimento e de cultura.

3) Exercício da cidadania na rede.

O Eixo 1 - Apropriação/Fluência/Empoderamento Tecnológico - diz respeito ao acesso, à apropriação, ao domínio e à fluência tecnológica, elementos necessários para reconhecer e transitar pela linguagem hipermidiática, condutora da cultura digital. É nesse eixo que dialogamos com os diferentes níveis de apropriação tecnológica e letramento digital, de forma a assegurar a necessidade de equidade de acesso, bem como oportunizar o empoderamento dos sujeitos por meio das tecnologias digitais de rede e reconhecer seu potencial comunicacional, educativo e político (MARCON, 2015).

O Eixo 2 - Produção/Autoria individual/coletiva de conhecimento e de cultura compreende os sujeitos como autores e produtores ativos de conhecimento e de cultura. As TDR potencializam a vivência de processos comunicacionais interativos, autorais e colaborativos. Com a abertura dos polos de emissão, a cibercultura autoriza o sujeito a expressar-se, interagir e participar. Supera-se a comunicação unidirecional e os limites temporais e espaciais, uma vez que se privilegia a interação todos-todos. É nesse eixo que correlacionamos a inclusão digital com a apropriação crítica e criativa das tecnologias digitais de rede, na qual os sujeitos, além de consumidores, são autorizados a criar, a produzir e a compartilhar informações, conhecimentos e cultura (MARCON, 2015).

O Eixo 3 - Exercício da cidadania na rede - refere-se à garantia de participação política dos sujeitos no ciberespaço e à valorização da diversidade social. Reconhecemos que a apropriação tecnológica pode acontecer de acordo com a realidade e com os interesses de cada sujeito; assim, cada um apropria-se das tecnologias de acordo com as suas necessidades individuais, coletivas ou comunitárias. Nesse eixo, fazemos uma interlocução com propostas 
que objetivam o reconhecimento das TDR como propulsoras de transformação das próprias condições de existência e do exercício da cidadania na rede (MARCON, 2015).

São palavras-chave do primeiro eixo: acesso, apropriação, domínio e fluência tecnológica. Entram, nesse eixo, assuntos referentes a diferentes níveis de apropriação tecnológica, letramento digital e oportunidade de acesso. Com relação ao segundo eixo, temos que os sujeitos, além de consumidores, têm oportunidade de exercer autoria crítica e criativa nas TDR, em que podem produzir e compartilhar informações, conhecimentos e cultura. Já no terceiro eixo, temos a garantia da participação política dos sujeitos no ciberespaço, assim como o reconhecimento de que as TDR podem impulsionar transformações relacionadas à condição de existência e da cidadania em rede do sujeito. Por meio desses três eixos, é possível reconhecer "[...] o potencial das tecnologias digitais de rede para a concretização de processos educativos autorais, criativos e colaborativos" (MARCON, 2015, p. 100), além da perspectiva política que envolve a apropriação das tecnologias digitais.

Essas dimensões do conceito de inclusão digital requerem pensar nas transformações que se imprimem na dinâmica escolar e no trabalho colaborativo entre os docentes. Hargreaves (2004), ao propor a discussão sobre a sociedade do conhecimento, anunciou desafios importantes para a educação e, em específico, para as escolas e os/as professores/as. As ideias de que as escolas devem ser movidas pela inventividade e pela criatividade, assim como pelo senso de comunidade, são atributos importantes para pensar as práticas pedagógicas na cultura digital, e estão em consonância com o conceito de inclusão digital aqui apresentado. Superar esquemas de formação padronizada para a construção de comunidades de aprendizagem profissional parece ser um elemento importante para a construção de propostas que envolvam os elementos da cultura digital no ensino escolar.

Um conceito que pode contribuir para pensar nesses processos coletivos de planejamento e prática pedagógica é o de docência compartilhada, que, de acordo com Nunes (2018, p. 68),

[...] é uma modalidade de docência que [...] é desenvolvida por mais de um professor(a), se configurando a partir desse desenvolvimento conjunto, como uma ação interdisciplinar que, por assim ser, se faz marcada por ações combinadas e/ou pensadas por eles(as) para o alcance dos mesmos propósitos.

No âmbito dos processos de inclusão digital, essas relações são observadas nas escolas, principalmente no desenvolvimento de projetos interdisciplinares que exigem "[...] ações 
pedagógicas centradas nas interações para produção de aprendizagens" (TRAVERSINI et al., 2012, p. 293). A efetivação de práticas compartilhadas exige dos/as docentes a “[...] percepção da importância do diálogo, elemento fundamental para articulação de ideias e ações” (NUNES, 2018, p. 70). Dessa maneira, consideramos que o conceito de docência compartilhada oportuniza o trabalho colaborativo no planejamento e no desenvolvimento das práticas pedagógicas (DAMIANI, 2008), e, de acordo com Traversini et al. (2012, p. 302), “[...] tem sido um permanente desafio de reinvenção da identidade docente".

Por fim, compreendemos que, para o desenvolvimento de processos de inclusão digital em contextos educativos escolares, há de considerarmos que esses elementos chaves operam em articulação. O planejamento intencional e a docência compartilhada na realização das práticas pedagógicas colaborativas que envolvem a utilização de tecnologias precisam romper a concepção instrumental e simplista que se tem sobre inclusão digital, ao compreender que esses processos acontecem a partir da fluência, da concepção autoral e do exercício da cidadania na rede.

\section{METODOLOGIA}

Este trabalho, como já apontamos, é um recorte da pesquisa "Inclusão digital em contextos educativos escolares: um estudo sobre a Rede Municipal de Ensino de Florianópolis/SC", o qual tem uma abordagem qualitativa, de natureza exploratória. Além de uma pesquisa bibliográfica sobre os principais eixos teóricos que sustentaram nossas análises, foi desenvolvida uma pesquisa de campo por meio de um estudo de caso, realizada por meio de pesquisa documental, observações simples e entrevistas estruturadas. Neste texto, apresentamos os resultados da coleta de dados realizada em sete escolas, referentes à observação simples de uma aula desenvolvida na sala informatizada com alunos do $4^{\circ}$ ou $5^{\circ}$ ano do Ensino Fundamental.

É importante compreendermos que o estudo de caso vem sendo utilizado com muita frequência porque atende a pesquisas com diferentes propósitos, como "[...] explorar situações da vida real cujos limites não estão claramente definidos e descrever a situação do contexto em que está sendo feita determinada investigação" (GIL, 1999, p. 73), elementos presentes também neste estudo. 
Lüdke e André (1986, p. 22) consideram que, dentro da concepção de estudo de caso que pretende "[...] não partir de uma visão predeterminada da realidade, mas apreender os aspectos ricos e imprevistos que envolvem uma determinada situação", a fase exploratória é fundamental para uma definição mais precisa do objeto que está sendo estudado. Nesse sentido, esta pesquisa caracteriza-se como exploratória e busca demonstrar o panorama da inclusão digital nas escolas da RME de Florianópolis/SC, sem, entretanto, deter-se na análise de elementos específicos, visto que a necessidade de entender o contexto geral vivenciado é maior do que a compreensão de elementos isolados. Quando se fala em pesquisa de caráter exploratório é, portanto, imprescindível compreender que estas “[...] são desenvolvidas com o objetivo de proporcionar visão geral, de tipo aproximativo, acerca de determinado fato" (GIL, 1999, p. 43), característica deste estudo.

Além disso, a fase exploratória é considerada um momento de especificar as questões ou os pontos críticos da constituição do todo, estabelecer contatos iniciais, localizar os informantes e as fontes de dados, ou, ainda, como uma "[...] visão de abertura para a realidade, tentando captá-la como ela é realmente, e não como se queria que fosse [...]" (LÜDKE; ANDRÉ, 1986, p. 22). Intencionamos, dessa forma, apresentar a realidade da inclusão digital nas escolas da RME de Florianópolis, observando momentos que irão, talvez, além ou aquém das expectativas de pré-pesquisa de campo.

Nossa escolha por realizar uma observação simples deve-se ao fato de que esse tipo de observação é adequado aos estudos qualitativos, “[...] sobretudo àqueles de caráter exploratório" (GIL, 1999, p. 112). Nesse tipo de observação, o pesquisador, “[...] permanecendo alheio à comunidade, grupo ou situação que pretende estudar, observa de maneira espontânea os fatos que aí ocorrem" (GIL, 1999, p. 111).

Foram selecionadas, por meio de amostragem intencional, 14 escolas para a realização da pesquisa de campo. Essas escolas foram eleitas a partir da sua localização geográfica, com o intuito de buscar atender aos diferentes bairros das regiões norte, sul, central, oeste e leste da ilha de Florianópolis/SC, bem como no continente. Para a concretização da pesquisa de campo, após aprovação do Projeto de Pesquisa no Comitê de Ética em Pesquisas Envolvendo Seres Humanos da Universidade do Estado de Santa Catarina - CEP/Udesc (Parecer consubstanciado $\mathrm{n}^{\mathrm{o}}$ 2.043.601, de 3 de maio de 2017), foi contatada a Secretaria Municipal de Educação de 
Florianópolis/SC para autorização da realização da pesquisa. Após aprovação, todas as escolas foram visitadas e sensibilizadas para a participação.

O protocolo de observação simples das atividades que estavam acontecendo na sala informatizada tinha as seguintes dimensões norteadoras: planejamento pedagógico, relação educador/a-educando/a, metodologia de ensino-aprendizagem, conceito de inclusão digital e relação professor/a regente-professor/a auxiliar de tecnologia educacional. Nessa perspectiva, o instrumento para o registro dessas dimensões foi elaborado a partir de problemas norteadores: Observa-se planejamento intencional na utilização da sala informatizada? Como acontecem as práticas pedagógicas na sala informatizada? Que tecnologias o/a professor/a utiliza com as crianças? Que dimensões do conceito de inclusão digital apresentam as atividades? Como acontece a relação entre professor/a regente da turma e professor/a auxiliar de tecnologia educacional? Além de outras observações relevantes para a pesquisa.

Apresentamos, a seguir, os resultados da pesquisa, que podem contribuir para o estabelecimento de reflexões sobre práticas pedagógicas no contexto da cultura digital.

\section{RESULTADOS}

A partir das observações realizadas nas sete escolas da RME de Florianópolis, os resultados foram organizados em cinco categorias: 1) planejamento intencional; 2) práticas pedagógicas; 3) tecnologias utilizadas; 4) dimensões do conceito de inclusão digital; e 5) relações entre o/a professor/a regente e o/a professor/a auxiliar de tecnologia educacional. A seguir, apresentaremos os dados conforme as categorizações, e, na seção posterior, faremos a discussão a partir do referencial teórico.

A primeira categoria do recorte desta pesquisa refere-se ao planejamento intencional na utilização da sala informatizada. Para tornar a leitura mais orgânica, optamos por recuar o registro das observações, conforme segue:

Na Escola 1, observou-se que a atividade era planejada e que utilizavam a tecnologia de informática para fazer buscas de imagens relacionadas ao tema abordado (Religiões).

Na Escola 2, observou-se que toda a condução da aula na sala foi planejada, que as crianças já conheciam as ferramentas do Google e que, nessa aula, 
estavam criando o seu primeiro questionário, com perguntas sobre a Copa do Mundo, que já deveriam ter elaborado e trazido de casa.

Na Escola 3, observou-se o planejamento das atividades. Tratava-se de uma pesquisa sobre a cidade de Florianópolis/SC, a qual os/as estudantes estavam realizando para dar continuidade a um projeto de uma revista da turma.

$\mathrm{Na}$ Escola 4, a atividade era planejada e previa a elaboração de uma apresentação na plataforma Drive, do Google. A atividade dava continuidade ao que já estava sendo elaborado pelos/as estudantes e cada apresentação tratava de um tema específico, de interesse do aluno.

Na Escola 5, observou-se que o/a educador/a planejou a utilização do Khan Academy até a metade da aula (atividades de matemática - tabuada - ou atividades de ciências), e, depois, as crianças puderam jogar diversos jogos.

Na Escola 6, observou-se que havia um planejamento prévio para a utilização da sala informatizada. As práticas pedagógicas foram previamente pensadas: vídeo, acesso ao site, escolha do conteúdo e elaboração de escrita para as crianças.

A Escola 7 igualmente apresentou um planejamento prévio da utilização da sala de aula informatizada; um vídeo foi apresentado e solicitada uma produção escrita pelas crianças.

A segunda categoria de análise deste estudo é sobre como aconteceram as práticas pedagógicas na sala informatizada:

Na Escola 1, os/as educandos estavam realizando uma pesquisa sobre religiões (católica, budista, religiões monoteístas, politeístas, etc.), iniciada na aula anterior. Os/as educandos/as foram divididos em duas duplas ou realizaram a atividade individualmente. Observou-se que pediam auxílio aos/às professores/as com frequência. As pesquisas eram feitas em sites de pesquisa (wiki, blogs) e Google imagens. Nos últimos 15 minutos, os/as educandos/as utilizaram a internet para recreação (principalmente jogos e vídeos sobre slime no YouTube). Foi liberado o acesso a sites de jogos educativos (Escola Games, Smartkids, Racha Cuca, Smartclass, GCmpris, Nosso Clubinho, Gartic e Slither.io.).

Na Escola 2, o/a professor/a orientou, no início da aula, como a atividade deveria ser realizada (formulário no Google Forms). Depois disso, explicou a ferramenta Gform e as possibilidades de perguntas. Durante a aula, circulou em todos os momentos pela sala, auxiliando os/as estudantes em suas dúvidas. Na Escola 3, as crianças deram sequência à atividade prevista anteriormente (elaboração de uma revista sobre Desterro). O/a professor/a orientou a pesquisa sobre temas diversos (Mercado Público, Primeiros Habitantes, Catedral, Centro Histórico, Casa da Câmara e Cadeia, Alfândega, Igreja do Rosário, Palácio e etc.). Os/as educandos/as realizaram pesquisas na internet e pesquisas de imagens para elaboração do texto no software Publisher. Observou-se orientação específica para cada dupla e também gerais para toda a sala.

$\mathrm{Na}$ Escola 4, o/a professor/a direcionou a realização da atividade em diálogo com as crianças. Observou-se que os/as educandos/as chegaram animados para a aula, organizaram-se individualmente em computadores e chromebooks. O/a professor/a guiou a atividade com auxílio do projetor multimídia, por meio do qual mostrava como deveria ser feito. Enquanto os/as 
educandos/as faziam a atividade, o/a professor/a orientava individualmente quando necessário. Foi observado que existia, também, ajuda mútua entre os/as educandos/as, aqueles que já possuíam certa fluência ajudavam os colegas que precisavam.

$\mathrm{Na}$ Escola 5, o/a professor/a orientou os/as educandos/as que tinham dúvidas sobre a execução da atividade no Khan Academy, deu sugestões sobre como responder às questões, checou como os alunos estavam utilizando os computadores e se estavam realizando a atividade, que envolvia a resposta às questões.

Na Escola 6, as crianças foram introduzidas ao assunto por meio de dois vídeos. Após assistirem, o/a professor/a questionou os/as educandos/as para o estabelecimento de um diálogo e orientou a próxima atividade. As crianças deveriam copiar o que estava escrito no site escolhido pelo/a professor/a. Não houve utilização de outras fontes ou recursos no computador e a cópia deveria ser feita no caderno.

$\mathrm{Na}$ Escola 7, as práticas pedagógicas estavam articuladas com o planejamento e os conteúdos trabalhados em sala de aula. Inicialmente, o/a docente apresentou um vídeo e, na sequência, solicitou uma produção textual para as crianças a partir da temática do vídeo.

A terceira categoria refere-se às tecnologias utilizadas pelo/a o/a professor/a com as crianças. Para melhor visualização dos dados coletados, organizamos o Quadro 1.

Quadro 1 - Tecnologias utilizadas pelo/a professor/a

\begin{tabular}{|l|l|}
\hline Escola 1 & $\begin{array}{l}\text { Google imagens e sites para pesquisa. Pastas no computador para salvar as imagens. } \\
\text { Sites de jogos educativos. }\end{array}$ \\
\hline Escola 2 & $\begin{array}{l}\text { E-mail, Google Drive e Google formulário. Internet, Google (busca de imagens para } \\
\text { a capa do formulário). }\end{array}$ \\
\hline Escola 3 & $\begin{array}{l}\text { Google imagens, Google maps e Google pesquisa. Sites de encurtador de links, e } \\
\text { Microsoft Publisher (editor de textos, colunas, inserir imagens, formatar títulos, } \\
\text { colunas, bordas, fundos, etc.). }\end{array}$ \\
\hline Escola 4 & E-mail institucional do Google e apresentações do Google Drive. \\
\hline Escola 5 & Site Khan Academy e sites de jogos. \\
\hline Escola 6 & Projetor multimídia e pesquisa em site definido pelo/a professor/a. \\
\hline Escola 7 & $\begin{array}{l}\text { Projetor de imagem para passar um vídeo (sem som). Ferramenta Word (pacote } \\
\text { LibreOffice) para a criação de um texto informativo. }\end{array}$ \\
\hline
\end{tabular}

Fonte: Os/as autores/as. 
A quarta categoria diz respeito às dimensões do conceito de inclusão digital das atividades desenvolvidas.

Na Escola 1, percebeu-se que os/as estudantes já dominavam alguns aspectos do uso da informática e internet e os/as professores/as os/as ajudavam em alguns aspectos mais técnicos. Tratava-se de pesquisa de imagens, a qual se focou no desenvolvimento do aprofundamento de conteúdo. Utilizaram a internet como fonte de informações. Tratou-se de um trabalho individual, autoral, de pesquisa e produção de conteúdo.

Na Escola 2, a atividade implicou a criação de conteúdo e compartilhamento - autoria individual e coletiva na elaboração das perguntas. Pressupostos de inclusão digital claros no planejamento do/a professor/a.

$\mathrm{Na}$ Escola 3, a atividade teve caráter cultural: produção de conteúdos individual/coletiva de conhecimentos. Trabalhou com a fluência tecnológica e, também, com a pesquisa e a produção de conhecimento/socialização, já que envolveu a elaboração de uma revista, que geralmente é impressa pelo/a professor/a.

$\mathrm{Na}$ Escola 4, apesar do recurso de internet utilizado possibilitar compartilhamento, as crianças compartilharam apenas com o/a professor/a, não havendo interação ou coletividade na realização da proposta. Entretanto, os/as educandos/as usaram o chat, e comunicaram-se entre si.

$\mathrm{Na}$ Escola 5, a atividade pressupôs fluência tecnológica (resolução de exercícios e jogos), centrando-se na utilização de ferramentas como mouse e teclado e acesso a sites.

$\mathrm{Na}$ Escola 6, os/as estudantes apenas realizaram leituras na internet em um site previamente escolhido pela professora e, portanto, não houve efetivamente uma apropriação dos recursos tecnológicos. As atividades não chegaram a apresentar as dimensões de fluência tecnológica.

$\mathrm{Na}$ Escola 7, observaram-se as dimensões de produção autoral/colaborativa de conhecimento, mesmo não utilizando a internet, considerando que o/a educador/a optou por utilizar vídeo e ferramentas de edição de textos.

Por fim, a quinta categoria trata das relações entre o/a professor/a regente da turma e o/a professor/a auxiliar de tecnologia educacional.

$\mathrm{Na}$ Escola 1, o/a professor/a auxiliar de tecnologia educacional e o/a professor/a regente trabalharam juntos/as, esclarecendo as dúvidas das crianças, em um planejamento prévio. Passavam pelos computadores para auxiliar as crianças.

Nas Escolas 2, 3 e 4, os/as professores/as regentes da turma não estavam presentes durante as atividades na sala informatizada. As atividades da sala foram desenvolvidas pelos/as professores/as auxiliares de tecnologia educacional.

Na Escola 5, o planejamento e o desenvolvimento foi do/a professor/a auxiliar de tecnologia educacional, entretanto o/a professor/a regente veio acompanhar a aula para conhecer o site que estava sendo utilizado.

Na Escola 6, os/as professores/as planejaram a aula previamente. O/a professor/a regente levou os/as educandos/as até a sala informatizada e explicou como ocorreria a aula, enquanto o/a professor/a da sala informatizada 
trabalhou com a parte técnica e também ajudou na orientação da atividade e organização da sala. No final da aula, o/a professor/a auxiliar de tecnologia educacional apenas observava, já que não havia necessidade de uma mediação técnica.

Na Escola 7, o/a professor/a auxiliar de tecnologia educacional ajudou em questões de fluência tecnológica, entretanto o/a professor/a regente demonstrou uma postura atuante e orientou a atividade. Foi observado que o/a professor/a auxiliar de tecnologia educacional ajudou a manter o ambiente em silêncio e também permitiu os/as educandos/as a irem ao banheiro.

Passamos, a seguir, para as discussões dos dados observados nas escolas, de modo a dialogar com os referenciais teóricos da pesquisa.

\section{DISCUSSÃO}

A análise da primeira categoria, referente ao planejamento intencional na utilização da sala informatizada, demonstra que, em todas as escolas, foi percebida a realização de planejamento prévio para a utilização da sala informatizada pelos/as professores/as. Em muitas situações, foi observado, também, que houve um encadeamento entre mais de uma atividade para a aula (Escolas 5, 6 e 7). A organização do planejamento educacional é fundamental para a realização do trabalho pedagógico: "A aula, lugar privilegiado da vida pedagógica, refere-se às dimensões do processo didático - ensinar, aprender, pesquisar e avaliar -, preparado e organizado pelo professor e seus alunos" (VEIGA, 2008, p. 267). Ao pensarmos as práticas observadas, percebemos que elas demonstram a intencionalidade dos/as professores/as no processo pedagógico, o que responde a uma questão importante do campo da Didática para o ensino escolar. Considerando, ainda, a especificidade do trabalho na sala informatizada, analisaremos o desenvolvimento de tais práticas na próxima categoria.

A segunda categoria, sobre as práticas pedagógicas desenvolvidas na sala informatizada, as observações realizadas nas escolas indicam diferentes formas de condução pelo/a professor/a das atividades, que reiteram, da mesma maneira, princípios distintos sobre a organização do processo pedagógico com as tecnologias digitais. Salientamos a importância de compreender tais práticas de forma a ultrapassar o pensamento reducionista sobre o uso das tecnologias na escola, como destacam Alonso et al. (2014, p. 155-156):

Nos últimos anos, problematizações e propostas sobre o aprender e ensinar escolar, a formação de professores, seja ela inicial ou continuada, têm 
fomentado algumas "saídas" para o "uso pedagógico", como denominado por várias iniciativas governamentais, das TDIC nas escolas. O maior problema de tais iniciativas tem a ver, sobretudo, com o pensamento, ainda reducionista, de que bastaria trabalhar algumas competências/habilidades técnicas para que estas tecnologias fossem mais bem aproveitadas no cotidiano dos estabelecimentos escolares.

Algumas dimensões para compreender as práticas pedagógicas são importantes de serem destacadas: a relação entre professor/a e alunos/as; a relação da proposta na sala informatizada com o planejamento educacional daquele nível de ensino; e as possibilidades de construção de saberes que emergem na cultura digital, como a autoria, a colaboração e a criatividade. Nesse sentido, percebemos que, em relação à primeira dimensão, em todas as escolas, foram observadas interações dialógicas entre professor/a e alunos/as. Pudemos observar, também, um bom nível de cooperação entre os/as estudantes na Escola 4.

Quanto à segunda dimensão, sobre a relação da proposta com o planejamento educacional do nível de ensino, das sete escolas em que as observações foram realizadas, evidenciamos em apenas três (Escolas 1, 6 e 7) a presença dessa articulação. Aqui significa apontar para o indício de que as atividades na sala informatizada, ainda que estruturadas com um planejamento prévio e uma continuidade do trabalho, como demonstramos na análise da primeira categoria, ainda não se relacionam com o trabalho pedagógico como um todo.

Por fim, indagamos a respeito da construção de saberes que podem ser desenvolvidos a partir das propostas, como a autoria, a colaboração e a criatividade. As observações apontam, em geral, para práticas pedagógicas que podem contribuir, em alguma medida, aos processos de construção autoral pelos/as estudantes, uma vez que atividades como pesquisa (Escola 1), elaboração de questionário (Escola 2), produção de uma revista (Escola 3) e produção de texto (Escola 7), vinculam-se a esse aspecto. Contudo, a prática observada na Escola 6, de utilização do computador para a cópia no caderno, vai de encontro aos pressupostos que estamos analisando. Em outra pesquisa, Machado (2016) discute a necessidade de reconstrução de práticas pedagógicas que reiteram modelos tradicionais de ensino, como a cópia, a partir da apropriação de outra tecnologia (o computador) no lugar do quadro.

Para analisar a terceira categoria, referente às tecnologias utilizadas pelo/a professor/a com as crianças, retomamos a discussão de Santaella $(2010,2013)$ acerca das cinco gerações tecnológicas desenvolvidas desde o século XIX. Como alerta a autora: 
Embora os três tipos de tecnologias precedentes à cultura do computador tenham provocado profundas transformações na vida humana, essas transformações não são comparáveis às mutações, [...], que a revolução digital está acarretando [...], especialmente para os processos educacionais (SANTAELLA, 2010, p. 18-19).

Ao analisar o Quadro 1, percebemos que as tecnologias utilizadas pelos/as professores/as se caracterizam pela geração das "tecnologias do acesso", as quais modificam as formas de relação e de diálogo com as informações e a experiência comunicativa:

Além de serem mídias de comunicação, as tecnologias do acesso são tecnologias da inteligência que alteram completamente as formas tradicionais de armazenamento, manipulação e diálogo com as informações, características que foram levadas para a comunicação móvel (SANTAELLA, 2013, p. 288).

Apesar de reconhecermos a emergência das tecnologias de conexão contínua, oportunizada pelo uso dos dispositivos móveis, como smartphones ou tablets, entendemos que as salas de aula informatizadas possuem um papel político e democratizador importante nas escolas, principalmente com relação aos educandos que não possuem acesso aos recursos digitais em seus domicílios. As experiências com os sites, os jogos e os recursos destacados na sala informatizada não cumprem, em sua totalidade, com os objetivos da prática pedagógica na cultura digital, mas, além de possuírem o potencial de ampliar o repertório dos/as educandos/as, oportunizam a fluência tecnológica, um dos eixos propostos no conceito de inclusão digital.

A quarta categoria diz respeito às dimensões do conceito de inclusão digital das atividades desenvolvidas. Conforme apresentamos anteriormente, esta pesquisa considera que os processos de inclusão digital deveriam perpassar, necessariamente, por três eixos: 1) Apropriação/Fluência/Empoderamento Tecnológico; 2) Produção/Autoria individual/coletiva de conhecimento e de cultura; 3) Exercício da cidadania na rede (MARCON, 2015).

Com relação aos dados coletados, observamos que todas as atividades propostas oportunizaram, em maior ou menor medida, o que concerne ao Eixo 1, principalmente com relação à fluência tecnológica. Para Teixeira (2010, p. 33, grifos do autor), em práticas pedagógicas na cultura digital, precisamos endossar a busca por fluência digital, entendida como "[...] processo dinâmico e provisório que se renova e aprimora na ação e na interação dos nós sobre e na rede de sentidos e suas interconexões". Isso acontece quando percebemos que 
as escolas, em suas práticas, superam a concepção simplista de acesso às tecnologias e sua instrumentalização (ALONSO et al., 2014).

Observamos, também, que as Escolas 1, 2, 3 e 4 igualmente trabalhavam na perspectiva do Eixo 2, uma vez que as atividades pressupunham produção/autoria individual ou coletiva de conhecimento e de cultura pelos/as estudantes. Para Lemos (2011, p. 19),

[...] mais do que dar acesso às tecnologias (uma condição técnica imprescindível e básica para qualquer projeto de inclusão digital), o desafio maior da inclusão cidadã à cultura digital é fazer com que os indivíduos possam produzir conteúdos próprios e distribuí-los livremente mantendo-se senhor de seus dados pessoais, garantindo-se a privacidade e o anonimato.

Nessa perspectiva, é desafio dos processos de inclusão digital promover uma apropriação produtiva das tecnologias digitais de rede, para que o sujeito se empodere desses recursos como autor/a, criador/a e produtor/a de conhecimento e de cultura, tendo como garantia as premissas de privacidade e de anonimato quando julgar necessário.

As atividades propostas na Escola 3, em nossa opinião, possuem elementos claros do Eixo 3 - Exercício da cidadania na rede. Como aponta Lemos (2011, p. 16),

[...] a inclusão digital não é alcançada apenas quando se dá computadores ou acesso à internet, mas quando o indivíduo é colocado em um processo mais amplo de exercício pleno de sua cidadania. A inclusão digital deve, consequentemente, ser pensada de forma complexa, a partir do enriquecimento de quatro capitais básicos: social, cultural, intelectual e técnico. [...]. Esses capitais devem ser estimulados, no caso da inclusão ao universo digital, pela educação de qualidade, pela facilidade de acesso aos computadores (e/ou similares) e à rede mundial de computadores, pela geração de empregos, ou seja, pela transformação das condições de existência (LEMOS, 2011, p. 16).

O desenvolvimento de uma revista, que pode extrapolar os muros da escola, bem como o compartilhamento do conhecimento autoral produzido pelas crianças, possuem uma dimensão política importante. Quando fazem uso desses recursos para demonstrar a qualidade da educação pública, para levar conhecimentos à comunidade local, assim como para transformar a própria realidade, igualmente oportunizamos o exercício da cidadania na Rede.

Ao iniciarmos a análise da quinta categoria, sobre as relações entre o/a professor/a regente da turma e o/a professor/a auxiliar de tecnologia educacional, cabe destacarmos algumas características da organização escolar da RME de Florianópolis. Dentre os/as profissionais que atuam no sistema de ensino, temos o/a "Professor Auxiliar de Tecnologia 
Educacional”. Esse/a profissional tem suas atribuições definidas pela Portaria No 596/2017, da Prefeitura Municipal de Florianópolis/SC (FLORIANÓPOLIS, 2017), de maneira a elucidar as atividades que devem ser realizadas na sala informatizada, bem como sua articulação com as práticas escolares como um todo (planejamento, avaliação, participação de reuniões e formações, por exemplo). Consideramos a presença do/a professor/a auxiliar de tecnologia educacional como um aspecto importante para o desenvolvimento das práticas pedagógicas. Em princípio, porque há um/a profissional habilitado/a para fazer a mediação tecnológica, com formação específica para isso. A ausência de formação para uso de tecnologias digitais é justificativa recorrente de gestores e professores para a não utilização desses recursos, como demonstramos em outro estudo (MACHADO, 2016). Dessa maneira, há um investimento para a qualificação do espaço da sala informatizada pelo gestor público, e isso resulta que, em todas as escolas observadas, encontramos esse/a profissional.

A figura do/a professor/a auxiliar de tecnologia educacional permite-nos discutir, também, a possibilidade da construção de uma docência compartilhada. Embora muitos/as teóricos/as discutam os processos pedagógicos na perspectiva de um/a professor/a e muitos/as estudantes, já temos estabelecidas experiências e pesquisas no campo da atuação de mais de um/a professor/a no processo de ensino (TRAVERSINI et al., 2012; NUNES, 2018). Nas atividades observadas, percebemos que, na maioria das escolas, houve uma atuação conjunta entre o/a professor/a regente e o/a professor/a auxiliar de tecnologia educacional (Escolas 1, 5, 6 e 7). Para analisar as formas de atuação nos processos observados, cabe destacarmos a importância do trabalho colaborativo entre os/as docentes, tanto no planejamento prévio quanto na execução da prática pedagógica. Segundo Damiani (2008, p. 218), “[...] o trabalho colaborativo entre professores apresenta potencial para enriquecer sua maneira de pensar, agir e resolver problemas, criando possibilidades de sucesso à difícil tarefa pedagógica". Nesse contexto, o/a professor/a auxiliar de tecnologia educacional possui um papel importante nas escolas, principalmente no que tange à articulação entre as dimensões tecnológicas e pedagógicas.

\section{CONCLUSÃO}


Por meio dos dados coletados, identificamos que todas as instituições apresentaram planejamento intencional das atividades que foram desenvolvidas na sala informatizada. As práticas pedagógicas desenvolvidas demonstraram interações dialógicas entre professor/a e alunos/as, articulação entre a proposta e o planejamento educacional do nível de ensino, e a construção de saberes embasados nas ideias de autoria, de colaboração e de criatividade na maioria das escolas. Geralmente as atividades eram realizadas em duplas ou trios, poucas vezes crianças trabalhavam individualmente. Isso se deve, sobretudo, ao número de computadores nas escolas ser menor que o número de educandos/as nas turmas.

Referente às tecnologias utilizadas pelos professores, identificamos que há uma variedade de recursos utilizados pelos/as docentes: sites educativos, editores de texto, plataformas de ensino, softwares de mapas, encurtadores de links, e-mails, sites de pesquisa de texto e imagem. Recursos que possibilitam o compartilhamento e a autoria colaborativa igualmente estavam entre os utilizados pelos/as educadores/as. Esses recursos, aliados aos planejamentos, possibilitaram-nos compreender que todas as escolas pesquisadas estabelecem relações com o Eixo 1 do conceito de inclusão digital proposto por este trabalho. Das sete escolas pesquisadas, quatro trabalharam na perspectiva da produção autoral, individual ou coletiva, de conhecimento pelos/as estudantes/as, e uma escola estava realizando uma atividade que contemplava também o Eixo 3 do conceito de inclusão digital. São resultados importantes e que trazem indícios qualificados referentes ao trabalho que vem sendo desenvolvido nas salas informatizadas.

Somente em uma escola percebemos uma subutilização do computador e dos recursos da internet, principalmente considerando que a pesquisa proposta deveria ser realizada em site específico, e os resultados, registrados no caderno. Observou-se que o computador foi usado apenas como um recurso de apoio. Entendemos que essa atividade pode fazer parte de um contexto maior, pois pensamos que esta pesquisa pode generalizar resultados sobre os processos de inclusão digital na RME de Florianópolis/SC, mas os dados observados trazem indícios importantes sobre algumas práticas que vêm sendo desenvolvidas. Assim, a subutilização da sala informatizada precisa ser problematizada, pois estudos mostram-nos que, para além do consumo de informações disponíveis na rede, as tecnologias podem ser apropriadas em outras dimensões, tais como a da autoria, da colaboração e da cocriação de conhecimentos. 
Diante disso, percebemos que esses espaços de aprender na cultura digital, planejados por professores/as regentes e por professores/as auxiliares de tecnologias educacionais em uma perspectiva de docência compartilhada, podem apontar a construção de um trabalho colaborativo entre docentes, de modo a articular as dimensões pedagógicas e técnicas nos processos de ensino na cultura digital.

Por fim, apontamos que a realização das observações simples nas salas informatizadas de sete escolas da RME de Florianópolis/SC indica o desafio de pensarmos cada vez mais em práticas pedagógicas flexíveis, orientadas, comunicativas, autorais e colaborativas referentes à utilização de tecnologias digitais de rede em contextos educacionais. Dessa maneira, podemos articular outras dimensões às práticas pedagógicas no contexto da cultura digital, que se vinculem aos princípios da inclusão digital e contribuam para o desenvolvimento de uma atuação crítica, autoral e cidadã na rede.

\section{REFERÊNCIAS}

ALONSO, Katia Morosov et al. Aprender e ensinar em tempos de Cultura Digital. EmRede Revista de Educação a Distância, Porto Alegre, v. 1, n. 1, p. 152-168, 2014. Disponível em: https://www.aunirede.org.br/revista/index.php/emrede/article/view/16. Acesso em: 31 mar. 2020.

BONILLA, Maria Helena. Educação e Inclusão Digital. GEC: Grupo de Pesquisa em Educação, Comunicação e Tecnologias. 2004. Disponível em: http://www.twiki.ufba.br/twiki/bin/view/GEC/MariaHelenaBonilla. Acesso em: 31 mar. 2020.

DAMIANI, Magda Floriana. Entendendo o trabalho colaborativo em educação e revelando seus benefícios. Educar em Revista, Curitiba, n. 31, p. 213-230, 2008. DOI: https://doi.org/10.1590/S0104-40602008000100013. Acesso em: 31 mar. 2020.

FLORIANÓPOLIS. Portaria $\mathbf{N}^{\mathbf{0}}$ 596/2017. Define atribuições do professor auxiliar de Tecnologia Educacional. Florianópolis: Prefeitura de Florianópolis, Secretaria de Educação, [2017]. Disponível em:

http://www.pmf.sc.gov.br/arquivos/arquivos/pdf/30_01_2018_14.18.55.4187be831d482c48ad 36a69238820a3b.pdf. Acesso em: 20 fev. 2021.

GIL, Antônio Carlos. Métodos e Técnicas de pesquisa social. 5. ed. São Paulo: Atlas, 1999. HARGREAVES, Andy. O ensino na sociedade do conhecimento. Educação na era da insegurança. Porto Alegre: Artmed, 2004. 
KENSKI, Vani Moreira. Educação e Tecnologias: o novo ritmo da informação. Campinas: Papirus, 2012.

LEMOS, André. Prólogo. In: BONILLA, Maria Helena; PRETTO, Nelson de Luca (Orgs.). Inclusão Digital: polêmica contemporânea. v. 2. Salvador: EDUFBA, 2011. p. 15-21.

LÜDKE, Menga; ANDRÉ, Marli E. D. A. Pesquisa em Educação: abordagens qualitativas. São Paulo: EPU, 1986.

MACHADO, Juliana B. Os desafios da formação docente no contexto da inclusão digital: análise de práticas pedagógicas. In: REUNIÃO CIENTÍFICA DA REGIÃO SUL - ANPED SUL, 11., 2016, Curitiba. Anais eletrônicos [...]. Curitiba: ANPEd, 2016. Disponível em: http://www.anpedsul2016.ufpr.br/portal/wp-content/uploads/2015/11/EIXO6_JULIANABRAND\%C3\%83O-MACHADO.pdf. Acesso em: 18 fev. 2021.

MARCON, Karina. Processos educativos e comunicacionais na Cibercultura: Explorando Ações de Inclusão Digital. Orientador: Adriano Canabarro Teixeira. 2008. 137 f. Dissertação (Mestrado em Educação) - Universidade de Passo Fundo, Passo Fundo, 2008.

MARCON, Karina. A inclusão digital de educadores a distância: Estudo multicaso nas Universidades Abertas do Brasil e de Portugal. Orientadora: Marie Jane Soares Carvalho. 2015. 251 f. Tese (Doutorado em Educação) - Universidade Federal do Rio Grande do Sul, Porto Alegre, 2015.

NUNES, Áurea Rodrigues. Docência compartilhada e prática docente num contexto interdisciplinar: desafios e contribuições na transição do $5^{\circ}$ para o $6^{\circ}$ ano do Ensino Fundamental. Orientadora: Laurizete Ferragut Passos. 2018. 137 f. Dissertação (Mestrado em Educação: Formação de Formadores) - Pontifícia Universidade Católica de São Paulo, São Paulo, 2018.

SANTAELLA, Lucia. A aprendizagem ubíqua substitui a educação formal? ReCeT - Revista de Computação e Tecnologia da PUC-SP, São Paulo, v. II, n. 1, p. 17-22, 2010. Disponível em: https://revistas.pucsp.br/index.php/ReCET/article/view/3852. Acesso em: 31 mar. 2020.

SANTAELLA, Lucia. Comunicação ubíqua: repercussões na cultura e na educação. São Paulo: Paulus, 2013.

SIBILIA, Paula. Redes ou Paredes: A escola em tempos de dispersão. Rio de Janeiro: Contraponto, 2012.

TEIXEIRA, Adriano Canabarro. Inclusão digital: novas perspectivas para a informática educativa. Ijuí: Editora Unijuí, 2010. Disponível em: http://usuarios.upf.br/ teixeira/livros/liAdriano_Canabarro_Teixeira_com_Capa.pdf. Acesso em: 20 fev. 2021.

TRAVERSINI, Clarice Salete et al. Processos de inclusão e docência compartilhada no III ciclo. Educação em Revista, Belo Horizonte, v. 28, n. 2, p. 285-308, 2012. DOI: https://doi.org/10.1590/S0102-46982012000200013. Acesso em: 31 mar. 2020. 
VEIGA, Ilma Passos Alencastro. Organização didática da aula: um projeto colaborativo de ação imediata. In: VEIGA, Ilma Passos Alencastro (Org.) Aula: gênese, dimensões, princípios e práticas. Campinas: Papirus, 2008. p. 267-298.

\section{NOTA}

${ }^{1}$ Apoiada pela Chamada Pública da Fundação de Amparo à Pesquisa e Inovação do Estado de Santa Catarina (FAPESC) No 01/2016 - Apoio à infraestrutura para grupos de pesquisa da Udesc: Grupo de Pesquisa Nexos: Teoria Crítica e pesquisa interdisciplinar - Sul.

Recebido em: 31/03/2020

Aprovado em: 13/07/2020 